\title{
Equal Channel Angular Pressing of a TWIP steel: Microstructure and mechanical response.
}

\author{
L. WANG ${ }^{1,2,}$, J. A. BENITO ${ }^{2,3}$, J. CALVO $^{2}$ and J. M. CABRERA ${ }^{2}$ \\ ${ }^{1}$ School of Materials Science and Engineering, Xian Petroleum University, Xian, \\ 710065, China; \\ ${ }^{2}$ Department of Materials Science and Metallurgical Engineering, ETSEIB, \\ Universitat Politècnica de Catalunya, Av. Diagonal 647, 08028 Barcelona, Spain; \\ ${ }^{3}$ Department of Materials Science and Metallurgical Engineering, EUETIB, \\ Universitat Politècnica de Catalunya, Comte d'Urgell 187, 08036 Barcelona, Spain;
} josep.a.benito@upc.edu ; jessica.calvo@upc.edu ; jose.maria.cabrera@upc.edu

*Corresponding author

E-mail address: richard0723@163.com

Tel. Phone: (34)-688180372

Materials Science Department, Pavelló E. ETSEIB

Av. Diagonal, 647. 08028 Barcelona.

Spain 


\section{Abstract}

A Fe-20.1Mn-1.23Si-1.72Al-0.5C TWIP steel with ultra-fine grain structure was successfully processed through Equal Channel Angular Pressing (ECAP) at warm temperature up to four passes following the $\mathrm{B}_{\mathrm{C}}$ route. The microstructure evolution was characterized by Electron Back Scattered Diffraction (EBSD) to obtain the grain maps, which revealed an obvious reduction of grain size, as well as a decrease of the twin fraction, with increasing number of ECAP passes. The texture evolution during ECAP was analyzed by Orientation Distribution Function (ODF). The results show that the annealed material presents Brass (B) as dominant component. After ECAP, the one pass sample presents $\mathrm{A}_{1}{ }^{*}$ and $\mathrm{A}_{2}{ }^{*}$ as the strongest components, while the two passes and four passes samples change gradually toward $B / \bar{B}$ components. TEM analysis shows that all samples present twins. The twin thickness is reduced with increasing the number of ECAP passes. Nano-twins, as a result of secondary twinning, are also observed in the one and two passes samples. In the four passes sample the microstructure is extensively refined by the joint action of ultra-fine subgrains, grains and twins. The mechanical behavior was studied by tensile samples and it was found that the yield strength and the ultimate tensile strength are significantly enhanced at increasing number of ECAP passes. Although the ductility and strain hardening capability are reduced with ECAP process, the present TWIP steel shows significant uniform deformation periods with positive work-hardening rates.

Key words: TWIP steel; ECAP; mechanical behavior; texture 


\section{Introduction}

High-manganese austenitic TWIP (Twinning-Induced Plasticity) steels exhibit an exceptional combination of high strength and outstanding ductility [1-3]. This optimal combination is especially attractive for automotive components such as structural and stabilizing parts. The increase in strength enables a reduction of the mass of the car body-in-white, and the increase in ductility admits complex component design.

These steels, when deformed at room temperature, exhibit twinning as a characteristic mechanism of plastic deformation. The main parameter which controls the deformation mechanisms is the stacking fault energy (SFE) of the austenitic matrix [2-3]. The magnitude of SFE controls the ease of cross-slip and twining mechanism [4]. TWIP steels have intermediate SFE $\left(15-40 \mathrm{~mJ} / \mathrm{m}^{2}\right)$ at room temperature due to their high content of manganese [5]. When deformation is applied, twinning generates a substructure in the microstructure where twin boundaries act by hindering the movement of dislocations and improving the strain hardening rate. This mechanism is also known as dynamic Hall-Petch effect or TWIP effect and it results in a retardation of localized deformation (necking) [6-7].

However, to some extent, the shortcoming of low yield strength of TWIP steels limits their wider application [8]. Grain refinement is considered a suitable way to strengthen the material, i.e. increase the yield strength, without changing the chemical composition and, therefore, maintaining the SFE value within the appropriate range [9-18]. In addition, other methods to increase the yield strength of TWIP steels have been investigated: pre-deformation $[19,20]$, recovery annealing $[21,22,23]$ as well as 
the careful control of the hot and cold rolling schedules, which is the typical production route.

Numerous researchers point out that the range of grain size which can be generated based on grain refinement is $1-25 \mu \mathrm{m}$ [9-12]. Within this range of grain sizes, the deformation mechanisms which are active for these steels are twinning combined with dislocation glide. However, there is still discussion about the effect of a further reduction in the grain size on the deformation mechanisms and mechanical properties. A possible way to further reduce the grain size to the sub-micron scale is Severe Plastic Deformation (SPD), and this approach is promising for microstructure control of TWIP steels. So far, only a few researches have focused on SPD of high-Mn TWIP steels [13-17]. Matoso [13] and Abramova [14] conducted high-pressure torsion (HPT) on different TWIP steels separately and both found significant improvements on hardness. On the other side, Matoso [13] indicated that strain hardening is lost after SPD due to exhaustion of twinning during the deformation. Equal Channel Angular Pressing (ECAP) is another suitable way of SPD to strengthen the material. This method is suitable to apply a significant amount of strain without reducing the cross sectional area of the workpiece. Given the relatively high strength of TWIP steels, the ECAP deformation has been usually performed at relatively elevated temperatures [15]. Timokhina [16] has performed ECAP on a FeMnC TWIP steel at different temperatures, and described characteristics of the microstructure related to the morphology of twins and dislocations. Haase et al. [17] conducted four passes of ECAP on a FeMnCAl TWIP steel, and showed the refinement of the microstructure 
and related it to the corresponding texture evolution and to the enhancement of the tensile strength with limited ductility. In addition, they also evaluated the effect of annealing on such properties.

In the present research, ECAP was applied to a similar composition of TWIP steel (FeMnCAl series) at a moderate temperature, i.e. $300^{\circ} \mathrm{C}$, for four passes, and the ultrafine-grained microstructure was analyzed by two techniques: Electron Backscatter Diffraction (EBSD) and transmission electron microscopy (TEM). The microstructure was finally correlated to the mechanical properties evaluated by tensile tests.

\section{Experimental procedure}

The chemical composition of the investigated steel is given in Table 1. The value of the stacking fault energy, calculated using the formula which appears in references $[5,24]$, is also included in the table. The material was supplied as a hot-rolled plate of $15 \mathrm{~mm}$ in thickness from which cylindrical specimens of $8 \mathrm{~mm}$ in diameter and 60 $\mathrm{mm}$ in length were extracted. These specimens were treated at $1200^{\circ} \mathrm{C}$ for 1 hour, in order to remove inhomogeneities and minimize segregation, followed by water quenching to room temperature.

The cylindrical samples were subjected to severe plastic deformation by the ECAP technique at $300^{\circ} \mathrm{C}$ to a maximum equivalent strain of 4 approximately (i.e. 4 passes). The corresponding processing route was $\mathrm{B}_{\mathrm{C}}$ (sample rotation of $90^{\circ}$ along its longitudinal axis in the same direction after each pass [25]). The ECAP die was 
manufactured with a tool steel, and the insert was made of two channels intersecting at an internal angle $\Phi=90^{\circ}$, with an outer arc of curvature $\varphi=37^{\circ}$ (see Fig. 1). According to Iwahashi's relationship, these angles promote approximately a true strain of 1 per pass [26]. The extrusion rate was $0.002 \mathrm{~m} / \mathrm{s}$, and molybdenum disulfide was used as a lubricant.

Micro-tensile specimens, with the dimensions specified in Figure 2, were machined from the middle of the longitudinal section of the samples processed by ECAP. Tensile testing was carried out using a Micro-test DEBEN machine at a cross head speed of $3.3 \times 10^{-3} \mathrm{~mm} / \mathrm{s}$ (quasi-static loading conditions). The fracture surfaces were examined under scanning electron microscope with a Field Emission Gun JEOL JSM-7001F (FE-SEM) operated at $20 \mathrm{kV}$. Some representative high resolution fracture graphs were taken for discussion.

The EBSD analyses were carried out with the same FE-SEM described above and were used by the characterization of microstructure and texture. The measures were performed on the transverse plane of the sample processed by ECAP (xy plane, see Fig. 1). The axis reference system xyz is also illustrated in Figure 1, indicating the extrusion direction " $\mathrm{x}$ " (ED), the normal direction " $\mathrm{y}$ " (ND) and the transverse direction "z" (TD). The samples were cut from the center of the ECAP specimens and then grinded and polished using diamond paste and a final stage with $0.02 \mu \mathrm{m}$ colloidal silica solution. Different scan step sizes were used: $3 \mu \mathrm{m}$ for the annealed condition, $0.2 \mu \mathrm{m}$ for the samples with 1 ECAP pass, $0.05 \mu \mathrm{m}$ for the samples with 2 ECAP passes and $0.03 \mu \mathrm{m}$ for the samples with 4 passes. The indexation rate was 
above $95 \%$ for initial condition sample and was maintained at $70 \%$ for the samples after ECAP procedure. They were post-processed utilizing the HKL Channel 5 software. The grain boundaries were identified as high angle boundaries in which misorientation was above $15^{\circ}$, while sub-grain boundaries were low angle boundaries with a misorientation between $2^{\circ}$ and $15^{\circ}$. For the twin boundaries a specific misorientation of $60^{\circ}$ over the $<111>$ axis was taken. The grain size for all the ECAP stages was determined from the detected grains by the software. In order to identify how dislocation density changes with the ECAP process, a calculation of the dislocation density has been performed according to the model of He et al [27] which obtain such values from conventional EBSD misorientation data. Dislocations are two-dimensional defects causing a relative displacement of the crystalline lattice. Through EBSD, components of dislocation vectors can be obtained and then dislocation density can be quantified [27]. These calculations has been done with the purpose of observed the general trend of the dislocation formation, understanding that the obtained values are approximate and better accuracy can be obtained by other known techniques.

A study by transmission electron microscopy for the investigation of the twin morphology, the formation of subgrains as well as the evolution of the dislocation arrangement in the deformed samples was also carried out. The specimens were analyzed in a Philips C2100 microscope operating at $200 \mathrm{kV}$. The samples for TEM observation were firstly mechanically polished and then thinned by twin-jet electropolishing in an electrolyte solution of 95 vol\% glacial acetic acid and 5\% 
perchloric acid at room temperature.

\section{Results}

\subsection{Mechanical properties}

The micro-tensile test results of the annealed TWIP steels as well as the samples processed by ECAP are shown in Figure 3 and Table 2. It is apparent that the yield strength (YS) and the ultimate tensile strength (UTS) increase with increasing number of ECAP passes. It is worth mentioning that the YS increment is stronger than the corresponding UTS increment. Similar behaviors have been reported in the literature [9,16-17]. It is also evident that the total elongation and ductility of the samples is reduced after each ECAP pass, although the values can be considered high, especially in terms of the reduction of area. In general, the elongation values are similar or larger than the ones reported for some conventional deep drawing steels, such as FeP04, Z St E $180 \mathrm{BH}$, high strength IF (HS) and Q St E 500 TM [28].

In order to get a better understanding of the ductility of the material, an analysis of the fracture surface was carried out. The images obtained are illustrated in Figure 4 and they correlate well with the results of elongation and reduction in area reported in Table 2. The fracture surface changes from a typical ductile appearance for the annealed material (nucleation and growth of large dimples and voids) to very small voids showing no coalescence. The sample corresponding to one ECAP pass in Figure $4 \mathrm{~b}$ displays a mixed behavior between the high ductility of the annealed sample (Figure 4a) and the limited ductility of the 4 passes ECAP sample (Figure 4d). It is 
also worth mentioning that the fracture surface of samples processed by ECAP does not display cleavage facets indicating that ductility mechanisms are still present, despite the limited strain hardening underwent by the material after ECAP processing. Although a limited dislocation motion is expected due to the microstructural refinement, the twinning mechanism could be promoting some ductility, as evidenced by the very small size of the voids and dimples observed in the samples processed by ECAP, especially those of 2 and 4 passes.

\subsection{Microstructure characterization}

\subsubsection{EBSD analysis}

Figure 5 illustrates the microstructure of the initial condition, i.e. annealed sample. It reveals that in this state the material exhibits a quite homogeneous microstructure composed of equiaxed grains with an average grain size of $69.2 \mu \mathrm{m}$, when taking twin boundaries into account, and $99 \mu \mathrm{m}$ when twins are not considered. The nature of grain boundaries indicate that almost no subgrains (plotted in green) are noticed and several annealing twins are present.

Figure 6 and Table 3 report the important features of the microstructures after 1, 2 and 4 passes. After the first pass the grains appear elongated in the shear direction and in some areas very fine equiaxed grains are noticed. In some of the elongated grains a large quantity of low-angle grain boundaries have been generated during the ECAP process, in other regions mechanical twins are visible (see Fig. 6b), but there are still some areas for which the density of subgrains or twins are still low. Even though the 
grain size is heterogeneous, the grain size of the new grains formed after 1 ECAP pass is $4.1 \pm 2 \mu \mathrm{m}$. After 2 ECAP passes the average grain size is further reduced. Although the microstructure is still quite heterogeneous, there is an increase of new ultrafine grains whereas the presence of large elongated grains vanishes in a clearly refined microstructure (Fig. 6c). At the look of Fig. 6d, it appears that the presence of mechanical twins has been reduced. However, it must be taken into account that at the step sizes used in the EBSD analysis and the lower indexing rate in the more deformed samples many fine mechanical twins are not visible by this technique. Consequently, it is not possible to calculate with accuracy the present fraction of twins. By contrast, a sharp increment of low angle grain boundaries can be observed, which entails a large reduction of elongated grains with a low density of defects in the form of dislocations cells or twins. Finally, after 4 passes all the material appears severely deformed. Few elongated grains are noticed since they have been fragmented and in many areas a large amount of ultrafine grains together with some twinning activity is observed (Figure 6e). The microstructure has been more refined and is hard to detect areas without a large concentration of defects, namely mainly subgrain boundaries. As for the two passes sample, the presence of twin boundaries detected by EBSD seems to be low. However, as explained above, it must be taken into account that the fine mechanical twins produced in this stage are missed during the EBSD analysis. It is also important to point out that the amount of low angle grain boundaries is still high, although, as shown in Table 3, the high angle grain boundaries are now predominant. That means that further ECAP passes would be able to promote larger amount of high 
angle grain boundaries, and therefore, larger strengths could be expected.

Table 4 illustrates the approximate values of dislocation density before and after ECAP procedure. As it was expected, there is a large increase of dislocation density after the first ECAP pass. In low SFE materials, cross slip of dislocations is more difficult, so that dislocation movement is restricted. Therefore, pile-up and proliferation of dislocations takes place, increasing drastically their density. A large increment in the dislocation density is also noticed after the second pass, and this coincides well with the aspect of the microstructures in Fig. 6, in which a large refinement takes place between the first and second ECAP pass. From this second pass a further refining of the microstructure is produced at four passes, but clearly at a slower rate due to the large deformation already applied to the material (Fig. 6c and 6e). Consequently, the calculated dislocation density has a lower but significant increase, showing a deceleration trend in the rate of dislocation formation.

\subsubsection{Texture analysis}

In this paper, the texture of the initial material was analyzed in triclinic symmetry, which refers to a $360^{\circ}$ rotation through the transversal direction (TD) of the ECAP die. Figure 7 shows the ODFs for the current TWIP steel in the initial condition before the ECAP process. It can be observed that the material presents monoclinic symmetry, that is, a repetitive behavior of the texture each $\phi_{1}=180^{\circ}$. The analysis of the ODF shows that a large number of grains are oriented close to Brass orientations, such as $\{110\}<112>$. This texture component is usually found in hot rolled FCC metals [29] 
and it has also been described for low SFE metals in the as-rolled condition [30]. For the specific case of TWIP steels, the evolution of Brass-type rolling texture has also been intensively studied [31-33]. In this case, after the last annealing step and the increase of annealing twins, the presence of Goss and $\beta$-fiber texture components have practically disappeared and the brass texture components have been reinforced. It should be noted that in low-SFE materials, twinning has a certain degree of influence on texture evolution, that is, a transition from Copper to Brass-type texture $[34,35]$.

The texture evolution of the present TWIP steel during the ECAP process was also analyzed in triclinic symmetry $\left(0^{\circ}<\phi_{1}<360^{\circ}\right)$ and the ideal orientations of deformation by simple shear were defined according to the ones suggested by Beyerlein et al. [36]. The texture evolution of the TWIP steel deformed by 1,2 and 4 ECAP passes and the ideal position for texture components for FCC materials deformed by simple shear are shown in Figure 8. Monoclinic symmetry can be observed in all cases, since the components are symmetrical every $180^{\circ}$ and the intensities of the $B / \bar{B}$ and $\mathrm{A} / \overline{\mathrm{A}}$ texture components are almost identical. The existence of monoclinic symmetry after 2 and 4 ECAP passes following $\mathrm{B}_{\mathrm{C}}$ route has not been observed [36], but it has been described in other studies $[37,38]$ which used a die with a similar setting to the one in the present case. When the die has an external angle $\Psi>0^{\circ}$ the textures exhibit some predominant orientations with a continuous distribution along the orientation fibers with simple shear texture, where two symmetrical areas can be observed [37].

After the first ECAP pass (Figure 8b), not a high texture index was achieved (2.1), 
and the areas of higher intensity coincide moderately well with ideal components of simple shear model showed in Fig. 8a, although some deviations exist, especially in the case of $\mathrm{C}$ and $\mathrm{A}_{2}{ }^{*}$ components. Deviations from ideal orientations are usual in ECAP processes and they are related to different processing factors $[17,36]$. For better comparison of the variation in intensity of the different shear texture components with the number of ECAP passes, the experimental intensities for every ideal component were normalized to the sum of all intensities of the shear texture components. The result is shown in Fig. 9, and it can be observed that the strongest component is $\mathrm{A}_{2}{ }^{*}$, which is not usual for high-SFE metals like $\mathrm{Cu}$ [Strotzky] or even for a low-SFE FeMnCAl TWIP steel processed by ECAP [17].

The other components show similar intensities to the FeMnCAl TWIP steel studied by Hasse et al. [17], except for the C component that appears with a lower intensity. With the second ECAP pass, a very low increase of the texture index is detected (2.2) but there is a gradual change in the intensities of the main components (Fig. 9). On one hand, there is a sharp decrease in the intensity of $\mathrm{A}_{1}{ }^{*}$ and $\mathrm{A}_{2}{ }^{*}$ components and on the other hand, there is a clear increase of the signal for $B / \bar{B}$ and $\mathrm{A} / \overline{\mathrm{A}}$ components. When the samples are deformed 4 passes by ECAP, a moderate increase of the texture index occurs (3.3). A further decrease of $\mathrm{A}_{1}{ }^{*}$ and $\mathrm{A}_{2}{ }^{*}$ is observed, which contrasts with the strengthening of the intensities for $B / \bar{B}$ and $\mathrm{A} / \overline{\mathrm{A}}$ components. The latter results in a strong presence of the $\beta$ fiber in the samples deformed by 4 ECAP passes. On the contrary, the $\mathrm{C}$ component shows a slight decrease of the signal with respect to the prior passes. 
The trend to develop the $\beta$ fiber orientations with increasing strain in low SFE metals has been pointed out before. The increase of $\beta$ fiber has been related to the strengthening of the $\mathrm{B}$ component $[36,38]$ mainly due to the replacement of $\mathrm{C}$ component orientations by B orientations $(\{112\}<110>)[36]$, which agrees well with the experimental data.

\subsubsection{TEM analysis}

A bright field TEM image of the annealed material is shown in Figure 10. Long straight dislocations with few interactions between them can be observed as a result of the low initial dislocation density. As displayed in EBSD studies, great changes in the microstructure are observed after one ECAP pass, with some austenite grains containing bundles of twins (Figure 6a). The twin thickness in this stage ranged between 400 and $800 \mathrm{~nm}$. One of these grains can be observed by TEM in Figure 11a. A careful observation allows viewing the high dislocation density inside the twins (Figure 11b). This fact has been described before [41] and it has been related to the large kinematic hardening observed in TWIP steels [42,43]. Grains with a more refined twin structure were also found, although less often than the grains with coarse twins, such as the one exposed in Figure 11a. In these cases secondary twinning was frequently observed (Figure 11c). The corresponding selected area electron diffraction (SAED) is shown in Figure 11d. The experimental SAED pattern enables to relate the extra diffraction spots to two different perpendicular twin systems formed on the (11-1) and (-111) planes [44,45]. This kind of structure has also been described in 
TWIP steels deformed by ECAP at $300{ }^{\circ} \mathrm{C}[16]$.

The TEM images corresponding to the samples after two ECAP passes are shown in Figure 12. In this stage an overall refinement of the microstructure was noted by the EBSD analysis (Fig. 6c) together with a significant increase of the dislocation density (Table 4). On the other hand, according to the EBSD analysis, the presence of twins was reduced when compared to the one ECAP pass samples. However, it was fairly easy to find grains in which bundles of twins were identified (Fig. 12a). The twin thickness was $80 \pm 25 \mathrm{~nm}$, which revealed a decrease of the mean value with respect to the one pass sample. This result agrees with the observation that twin thickness declines as the grain size decreases [8]. Inside these primary twins two main features can be observed. The first one is that the dislocation density was again very high, as in the one pass ECAP sample (Figure 12b). The second feature is the presence of numerous nano-twins (Figure 12c), which can be detected in the experimental SAED pattern in Figure 12d. The formation of a secondary twinning system inside primary twins has been well described in some TWIP steel processed by ECAP [16], but it seems to be less frequent in others [17], since in the last case the presence of nano-twins was mainly described inside shear bands and subgrains.

After four ECAP passes at $300^{\circ} \mathrm{C}$, the microstructure has been further refined but, in this case, the dislocation density and the grain size have changed slightly in comparison with the two ECAP passes sample. This implies that the capability of the material to increase the density of defects is lower [46]. The highly disordered microstructure after four ECAP passes is depicted in Figure 13. In most of the grains 
the presence of subgrains with sizes that are around $100 \mathrm{~nm}$ and even lower can be observed. Other grains present thin and short twins with a thickness within a range of $30-40 \mathrm{~nm}$.

\subsection{Deformation stages}

Figure 14 illustrates the true tensile stress, $\sigma$, and strain hardening rate curves, $(\mathrm{d} \sigma / \mathrm{d} \varepsilon)$ vs strain, $\varepsilon$, and the $\ln (\mathrm{d} \sigma / \mathrm{d} \varepsilon)$ vs $\ln \sigma$ plots for the annealed specimen and the samples after 1, 2 and 4 ECAP passes. The $\ln (\mathrm{d} \sigma / \mathrm{d} \varepsilon)-\ln \sigma$ plot of the annealed sample shows that the plastic deformation can be divided into five stages. First, a dramatic decrease in the strain range of $0-0.028$ (stage A); second, a constant value up to 0.1 strain (stage B); third, a slightly increase until 0.16 strain (stage C); then, there is another steady region (stage D) in the strain of $0.16-0.27$, and finally, over 0.27 strain, the strain hardening rate starts to drop until the failure of the specimen (stage E). According to different authors $[47,48]$, these stages can be related to the following mechanisms: The transition point from stage A to stage B corresponds to the onset of twinning within grains deformed by multi-slip; the constant level of stage B can be due to the introduction of primary deformation twins; then the increase period of stage $\mathrm{C}$ can be associated to the activation secondary deformation twinning; the following constant plateau (stage D) is attributed to a decrease of the twinning rate; the stage $\mathrm{E}$ finally takes place when twinning activity slows down and the plastic instability occur. This behavior is similar to the one found for others FeMnCAl TWIP Steels, with no increase of the strain hardening rate during stage $\mathrm{B}$ and with a little or even no 
increase during stage C $[41,48,49]$. The presence of aluminum in TWIP steels increases the SFE which promotes an overall decrease in the mechanical twinning activity. This decrease is even more pronounced in secondary twinning since secondary twinning systems are less active [49] and is reflected in lower strain hardening rates during stage B and especially in stage C than other TWIP steels such as FeMnC TWIP steels [44,49,50].

After the first ECAP pass at $300{ }^{\circ} \mathrm{C}$, there is a significant increase of the yield strength together with a reduction of the elongation. However, it must be noted that the material still retains some strain hardening ability since in the evolution of strain hardening with strain (Fig. 14c and 14d) the material hardens up to a true strain of 0.15. After the high decreasing rates of stage A there is a period in which a low decreasing rate of hardening can be observed, called stage B. This stage ends in a stabilization zone (stage C) in which a slight increase of the strain hardening can be detected. After it, the strain hardening decreases up to the necking point.

The Figure 14e and 14f show the evolution of strain hardening during tensile test for the samples after two ECAP passes. It is interesting to note that the strain hardening follows the same pattern than the one ECAP pass sample: a stage B of smooth reduction can be defined with a further recovery period in which even a slight increase of strain hardening is observed (stage $C$ ). From stage $C$, the strain hardening decreases during stage $\mathrm{E}$ up to the necking at a true strain value of 0.11 .

Finally, in the evolution of the strain hardening rate during tensile test for the four ECAP passes sample (Fig. 14g and 14h), the uniform elongation has decreased with 
respect to the 2 ECAP pass samples (0.046) and the total elongation is reduced until 7\%. In this case, although the material retains some strain hardening ability, no intermediate stages in which the work-hardening rate stabilizes or increases have been detected.

\section{Discussion}

With respect to the mechanical properties of the present FeMnCAl based TWIP steel, after the first ECAP pass at $300^{\circ} \mathrm{C}$, there is a significant increase of the yield strength. This behavior has also been described in other previous studies on severe plastic deformation by ECAP at similar temperatures for FeMnC based TWIP steels [16] and FeMnCAl based TWIP steels [17]. The high yield strength comes from the large increase of dislocation activity forming a large number of subgrains together with the interaction with mechanical twins [32,33]. Despite the large SFE values at $300^{\circ} \mathrm{C}$ [5,9], mechanical twinning has been repeatedly observed in a large number of austenite grains for the present TWIP steel, in the same way than in the other TWIP steels processed by ECAP $[16,17]$. The TEM analysis has shown that inside these fine mechanical twins the dislocation density is very high (Fig. 10b).

Together with the increase of strength, there is a reduction of the elongation. However, the material retains a significant uniform elongation (up to 0.15 ) and even positive work-hardening rates (Fig. 14d), which is rather unusual in ECAP processed materials [51]. The FeMnCAl TWIP steel deformed at $300^{\circ} \mathrm{C}$ by Haase et al [17] also shows a similar uniform elongation and work-hardening period, but the work hardening rate is 
not positive. This fact could be explained taking into account the initial microstructure of the present TWIP steel after one ECAP pass and the deformation mechanisms of TWIP steel in tensile tests at room temperature. In the first point, from the analysis of microstructure by EBSD in Figure 6 it is clear that, although a significant number of elongated grains with high density of subgrains or mechanical twins can be observed, there are some grains that show less number of defects. This is in line with the studies of Barbier et al. [52] in which was compared the microstructural evolution of a FeMnC TWIP steel in tensile and shear test. In the case of shear test, the number of twinned grains was only $70 \%$, whereas for tensile test the $90 \%$ of grains presented at least one active twining system. In addition, the microstructure of the FeMnCAl after one ECAP pass was defined as "bimodal" reflecting the existence of certain areas with a less intense refining of the microstructure [17]. In the second point, during the tensile tests at room temperature the SFE of the FeMnCAl TWIP steel is again low, which increases twinning activity. In addition, tensile deformation favor the activation of secondary twinning at very low strains [52]. Therefore, the combination of low-deformed grains and the greater ease for twinning in room-temperature tensile tests may explain the positive work-hardening rates for one pass ECAP samples. In this sense, the study of the microstructural evolution during tensile tests of the FeMnCAl TWIP steel previously deformed by ECAP reinforces this reasoning since mechanical twinning was considered the main deformation mechanism [17]. It was found that, after one ECAP pass, a great number of new mechanical twins was observed at low strains (5\% and 10\%) interacting with the pre-existing dislocation 
cells. New mechanical twins were easily detected even in the samples with four ECAP passes when strained to $5 \%$ and $10 \%$. In addition, secondary twinning was detected inside primary twins, probably due to the high applied stress in these samples, which shows the work-hardening ability of the TWIP steel after ECAP processing [17].

In the case of two ECAP passes at $300{ }^{\circ} \mathrm{C}$, the same trend is observed, i.e. there is an increase of the strength while the total elongation decreases. Both aspects can be related to the evolution of the microstructure since the EBSD analysis in Figure 6 shows a significant reduction of the size of subgrains as a result of a high dislocation activity. Twinning activity was also observed in the TEM analysis in Figure 12, and it must be pointed out the large presence of nanotwins inside the primary twins due to secondary twinning. The interaction between both mechanisms reduces sharply the mean free path of dislocations that renders a large increase of strength.

Regarding work hardening after two ECAP passes, the behavior is similar to that of the one ECAP pass, with a slight decrease in the strain-hardening period (up to 0.11). The material maintains an intermediate stage in which the work-hardening rate is positive (Fig. 14f). As explained above, this good behavior may be related to the existence of twinning as main deformation mechanism in tensile tests at room temperature. In this case, this response is much better than for the other FeMnCAl steel processed by ECAP since in the latter the hardening period is clearly shorter $(\approx 0.03)$ with no signs of any intermediate recovery stage [17]. Comparing the evolution of the microstructure in both FeMnCAl TWIP steels, it seems fairly similar 
and thus it is difficult to find a reason for this difference. A possible explanation may be the differences in the ECAP process, as for example the presence of an outer arc of curvature in the die of the present work $\left(\Psi=37^{\circ}\right)$. As a result of this outer angle, the equivalent strain achieved in every pass is 1.0 for the present work, less than the 1.155 achieved in [17]. Another reason could be that the present steel shows a greater easiness for secondary twinning. Secondary twinning systems have been observed in the present steel after one and two ECAP passes, more commonly after two passes.

In the case of FeMnC based TWIP steels, the overall strain hardening values are higher than the ones for the present FeMnCAl steel [16] which can be again related to the larger twinning activity of FeMnC based TWIP steels [49]. However, there is a continuous decrease of the strain hardening for the FeMnC samples processed at $300^{\circ} \mathrm{C}$. In this case, it is possible that the larger twinning activity at $300^{\circ} \mathrm{C}$ has exhausted faster the ability of the steel to harden after the ECAP passes at that temperature [16].

Finally, the samples with four ECAP passes showed the maximum strength with a further reduction of elongation. It coincides well with the analysis by EBSD and TEM that shows a large refinement of the microstructure. Many subgrains formed in previous ECAP passes have led to new fine grains with equiaxed morphology, and the remaining dislocation cells have reduced the diameter up to $100 \mathrm{~nm}$ or less as well as mechanical twins appeared distorted with twin thicknesses around 30-40 nm. In addition, the evolution of dislocation density in Table 4 shows that the dislocation density has increased at a very low rate during the third and fourth passes. All these 
observations lead to the conclusion that after 4 ECAP passes the present TWIP steel have a reduced ability to further refinement of the microstructure. However, some strain hardening is visible (up to 0.046 ) and the steel retains a $7 \%$ elongation to fracture.

To explain this good behavior it is necessary to compare the current FeMnCAl steel with the one processed by ECAP by Hasse et al. [17]. It can be said that the microstructure in the latter steel seems to be a bit more refined than in the present case, probably due to the higher equivalent strain achieved in each pass, as described above. However, it is important to note that even under those conditions mechanical twinning was observed in that steel with intense presence of secondary twinning. This was reflected in an elongation of $14 \%$ and a short strain-hardening period. In the current TWIP steel it also seems likely that twinning should be acting during the tensile test and that fact would help to explain the short but significant existence of a strain hardening period and little elongation. Finally, it can be concluded that the presence of strain hardening is in agreement with the analysis of the fracture surface for the samples with four ECAP passes that shows still some dimples (Fig. 4).

Another important topic is the evolution of texture during ECAP processing of TWIP steels, and its implications in the mechanical properties described above. In the Fig. 9 the main shear texture components after one ECAP pass were presented, and the direct comparison with the texture data of the FeMnCAl TWIP steel also processed by ECAP at $300^{\circ} \mathrm{C}$ shows similar behavior, although with some significant variation. The main difference is the higher intensity of the $\mathrm{A}_{2}{ }^{*}$ and a slight decrease of $\mathrm{A}_{1}{ }^{*}$ texture 
components in the present steel [17]. The strong presence of $\mathrm{A}_{2}{ }^{*}$ component has been reported before in low-SFE metals: Barbier et al. [52] reported that in shear tests of a FeMnC TWIp steel, $\mathrm{A}_{2}{ }^{*}$ and $\mathrm{A}_{1}{ }^{*}$ components showed larger intensities than the other shear components, although in this case the equivalent strain was low (0.3) comparing with the one achieved in one ECAP pass. Chowdhury et al. [53] showed that $\mathrm{A}_{2}{ }^{*}$ was the main component of texture for Ag processed by ECAP in a die with an outer angle of $20^{\circ}$ and similar result was obtained by Beyerlein and Toth [36]. In the last case, the authors linked these results with mechanical twinning since the formed twins have $\{111\}<112>$ orientations which belong to $\mathrm{A}_{2}{ }^{*}$. To finish with the comparison in the case of one ECAP pass, it is interesting to remark than in the present steel the normalized intensity for $\mathrm{C}$ component is slightly lower than for the case of the FeMnCAl in [17]. However, in both cases the obtained intensity for $\mathrm{C}$ is clearly lower than in the case of a high-SFE metal as $\mathrm{Cu}[39,40,54]$.

The evolution of texture index for the present steel with ECAP passes more or less coincides with the one for TWIP steel in [17]. In the second pass there is a negligible increase of texture strength, being the increase more remarkable after four passes. The analysis made in [17] shows that normally high-SFE metals show no increase of texture strength between 2 and 4 passes, which could be related to a saturation of deformation mechanisms [17,40,54]. However, for metals with low-SFE such as silver or the FeMnCal TWIP steel which deform by twinning [17,53], an increase of the texture strength has been reported. In this case, the increase of texture strength detected in the present steel could reinforce the idea that in this topic low-SFE metals 
behave different than high-SFE metals when deformed by ECAP.

Regarding the evolution of the main shear texture components with subsequent ECAP passes, it must be said that with the successive changes in the position of the samples following the route $\mathrm{Bc}$, there is a large decrease in the $\mathrm{A}_{2}{ }^{*}$ and $\mathrm{A}_{1}{ }^{*}$ accompanied by a clear increase of the signal for $B / \bar{B}$ and $\mathrm{A} / \overline{\mathrm{A}}$ components. The existence of a large decrease of both $\mathrm{A}_{2}{ }^{*}$ and $\mathrm{A}_{1}{ }^{*}$ components has been no reported in the other low-SFE metals studied [17,53], although for the FeMnCAl TWIP steel in [17] $\mathrm{A}_{2}{ }^{*}$ clearly decreases and $\mathrm{A}_{1}{ }^{*}$ shows a little decrease in its intensity. It could be that the drop in the signal of these components might be related to the difficulties of EBSD analysis to detect all the new twins formed at high deformations. On the other hand, the increase of $B / \bar{B}$ components and more generally the increase of the $\beta$ fiber with increasing strain in low-SFE metals have been previously reported [36]. This increase has been related basically to the strengthening of the $\mathrm{B}$ component, mainly due to the replacement of C component orientations by B orientations $(\{112\}<110>)[36,38]$. This reasoning coincides partially well with the present texture evolution since a clear decrease of $\mathrm{C}$ component is observed after four passes.

The general evolution of the texture with ECAP in the present steel has rather common points with other studies in which the trends in texture of low-SFE materials have been studied [36,55-57]. Here it must be assumed that texture is largely influenced by small changes in the features of the process what implies some variations even for the same metal. But in general, with the diminution of SFE values a decrease of the $\mathrm{C}$ component together with an increase of $B / \bar{B}$ components is 
expected. This general trend agrees well with the texture evolution of the present steel.

Regarding the relationship between texture and deformation mechanisms, it has been suggested by Suwas et al. [30,56] that the effect of decreasing SFE on texture evolution during ECAP could be compared to the texture development in cold rolling procedure, and some correspondence between texture components is proposed: $\mathrm{S} \rightarrow \mathrm{A}_{1}{ }^{*}, \mathrm{Cu} \rightarrow \mathrm{C}$, Brass $\rightarrow B / \bar{B} \quad[17,30]$. According to this, $\mathrm{A}_{1}{ }^{*}$ and $\mathrm{C}$ components should be reduced whereas $B / \bar{B}$ components should be strengthened by ECAP strain as the SFE decreases. On the basis of this assumption, Haase et al. defined the texture obtained for the FeMnCAl as "transition texture" [17]. This was driven by the strong presence of $\mathrm{C}$ component together with the increase of $B / \bar{B}$ components with ECAP passes. A hypothesis was formulated in which the strong $\mathrm{C}$ presence would be related to the dislocation glide as main deformation mechanism and the increase in $B / \bar{B}$ components would correspond to the effect of deformation twins. In the case of the present FeMnCAl steel, the evolution of texture corresponds better with the proposed correspondence proposed by Suwas et al., since $\mathrm{C}$ and $\mathrm{A}_{1}{ }^{*}$ are reduced and $B / \bar{B}$ increased with successive ECAP passes. This would mean that the importance of deformation by twinning would be greater in the present case, and this could help to explain the existence of positive work-hardening rates in the intermediate stages during tensile deformation for the one and two pass ECAP samples and the longer periods of uniform elongation for the samples after two and four ECAP passes. 


\section{Conclusions}

In the current work, the isothermal equal channel angular pressing of a Fe-20.1Mn-1.23Si-1.72Al-0.5C TWIP steel was successfully performed. The corresponding mechanical behavior and microstructure evolution was investigated. The main findings were:

1) The yield strength and ultimate tensile strength increased significantly during the ECAP procedure. On the other hand, the ductility decreased with increasing of number of passes. The fracture surface analysis showed that the number and size of dimples decreased with increasing number of ECAP passes, up to four ECAP passes, for which the sample showed limited ductile fracture features.

2) After one and two ECAP passes, the present FeMnCAl based steel showed hardening up to 0.15 and 0.12 strain, respectively. In the strain hardening evolution with strain, periods of constant strain hardening rate and subsequent zones of a slight increase of the strain hardening rate were observed. This behavior could be related to the ability of the material to deform by twinning, activating primary and secondary twin systems. After 4 passes the strain hardening rate decreased constantly with strain but still showing some uniform elongation.

3) The evolution of the microstructure after one and two ECAP passes showed that the grains were elongated in the shear direction and that a large number of subgrains were introduced. At the same time, mechanical twins were created with smaller thickness as deformation proceeded. Secondary twinning was active in the first and second ECAP 
passes. During the third and fourth passes, dislocation and twinning activity led to a further refinement of the microstructure, hindering further deformation and resulting in the low hardening rate obtained during the tensile test of the four ECAP passes sample.

4) After the ECAP process, simple shear textures were identified. One ECAP pass samples presented a preference toward $\mathrm{A}_{2}{ }^{*}$ component, while the two and four ECAP passes samples showed a preference toward the $\beta$ fiber, represented by its $B / \bar{B}$ components. This increase of $B / \bar{B}$ components together with the decrease of $\mathrm{C}$ shear texture component may indicate a large effect of deformation twinning in the processing of FeMnCAl by ECAP at $300^{\circ} \mathrm{C}$.

\section{Acknowledgments}

The present work has been financially supported by China Scholarship Council (CSC) and the Spanish Ministry of Economy and Competitiveness through project MAT2014-59419-C3-1-R. 


\section{References}

[1] Soulami A, Choi KS, Shen YF, Liu WN, X. Sun and Khaleel MA (2011) On deformation twinning in a $17.5 \%$ Mn-TWIP steel: A physically based phenomenological model, Mater Sci Eng A 528:1402-1408.

[2] Frommeyer G, Brux U and Neumann P (2003) Supra-Ductile and High-Strength Manganese-TRIP/TWIP Steels for High Energy Absorption Purposes, ISIJ Int 43:438-446.

[3] Grassel O, Kruger L, Frommeyer G and Meyer LW (2000) High strength Fe-Mn-(Al, Si) TRIP/TWIP steels development-properties-application, Int J Plast 16:1391-1409.

[4] Vercammen S, Blanpai B, Cooman BC and Wollants P (2004) Cold rolling behaviour of an austenitic Fe-30Mn-3Al-3Si TWIP-steel: the importance of deformation twinning, Acta Mater 52:2005-2012.

[5] Allain S, Chateau JP, Bouaziz O, Migot S and Guelton N (2004) Correlations between the calculated stacking fault energy and the plasticity mechanisms in Fe-Mn-C alloys, Mater Sci Eng A387-389:158-162.

[6] Bouaziz O and Guelton N (2001) Modelling of TWIP effect on work-hardening, Mater Sci Eng A319-321:246-249.

[7] Shiekhelsouk MN, Favier V, Inal K and Cherkaoui M (2009) Modelling the behaviour of polycrystalline austenitic steel with twinning-induced plasticity effect, Int J Plast 25:105-133.

[8] Rahman KM, Vorontsov VA and Dye D (2015) The effect of grain size on the twin initiation stress in a TWIP steel, Acta Mater 89:247-257.

[9] Ueji R, Tsuchida N, Terada D, Tsuji N, Tanaka Y, Takemura A and Kunishige K (2008) Tensile properties and twinning behavior of high manganese austenitic steel with fine-grained structure, Scripta Mater 59:963-966.

[10] Danaf EE, Kalidindi SR and Doherty RD (2001) Influence of deformation path on the strain hardening behavior and microstructure evolution in low SFE FCC metals, Int J Plast 17:1245-1265. 
[11] Tewary NK, Ghosh SK, Bera S, Chakrabarti D and Chatterjee S (2014) Influence of cold rolling on microstructure, texture and mechanical properties of low carbon high Mn TWIP steel, Mater Sci Eng A 615:405-415.

[12] Bouaziz O, Allain S and Scott C (2008) Effect of grain and twin boundaries on the hardening mechanisms of twinning-induced plasticity steels, Scripta Mater 58:484-487.

[13] Matoso MS, Figueiredo RB, Kawasaki M, Santos DB and Langdon TG (2012) Processing a twinning-induced plasticity steel by high-pressure torsion, Scripta Mater 67:649-652.

[14] Abramova MM, Enikeev NA, Kim JG, Valiev RZ, Karavaeva MV and Kim HS (2016) Structural and phase transformation in a TWIP steel subjected to high pressure torsion, Mater Lett 166:321-324.

[15] Bagherpour E, Reihanian M and Ebrahimi R (2012) On the capability of severe plastic deformation of twining induced plasticity (TWIP) steel, Mater and Des 36:391-395.

[16] Timokhina IB, Medvedev A and Lapovok R (2014) Severe plastic deformation of a TWIP steel, Mater Sci Eng A 593:163-169.

[17] Haase C, Kremer O, Hu WP, Ingendahl T, Lapovok R and Molodov DA (2016) Equal-channel angular pressing and annealing of a twinning-induced plasticity steel: Microstructure, texture, and mechanical properties, Acta Mater 107:239-253.

[18] Saha R, Ueji R and Tsuji N (2013) Fully recrystallized nanostructure fabricated without severe plastic deformation in high-Mn austenitic steel, Scripta Mater, 68(10):813-816.

[19] Bouaziz O, Allain S, Scott CP, Cugy P and Barbier D (2011) High manganese austenitic twinning induced plasticity steels: A review of the microstructure properties relationships, Curr. Op. in Solid State and Mater Sci., 15: 141-168.

[20] Kusakin P, Belyakov A, Haase C, Kaibyshev R and Molodov DA (2014) Microstructure evolution and strengthening mechanisms of Fe-23Mn-0.3C-1.5Al TWIP steel during cold rolling, Mater Sci Eng A, 
617(1):52-60.

[21] Bouaziz O, Scott CP and Petitgand G (2009) Nanostructured steel with high work-hardening by the exploitation of the thermal stability of mechanically induced twins, Scripta Mater, 60(8):714-716.

[22] Haase C, Barrales-Mora LA, Roters F, Molodov DA and Gottstein G (2014) Applying the texture analysis for optimizing thermomechanical treatment of high manganese twinning-induced plasticity steel, Acta Mater, 80:327-340.

[23] Zhou P, Liang ZY, Liu RD, Huang MX (2016) Evolution of dislocations and twins in a strong and ductile nanotwinned steel, Acta Mater, 111:96-107

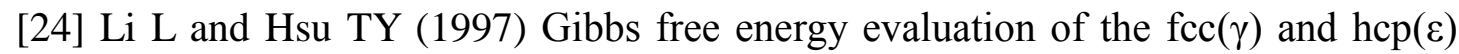
phases in Fe-Mn-Si alloys, Calphad 21.3:443-448.

[25] Valiev RZ and Langdon TG (2006) Principles of equal-channel angular pressing as a processing tool for grain refinement, Prog Mater Sci 51:881-981.

[26] Iwahashi Y, Horita Z, Nemoto M and Langdon TG (1997) An investigation of microstructural evolution during equal-channel angular pressing, Acta Mater 45:4733-4741.

[27] He W, Ma W and Pantleon W (2008) Microstructure of individual grains in cold-rolled aluminium from orientation inhomogeneities resolved by electron backscattering diffraction, Mater Sci Eng A 494:21-27.

[28] Frommeyer G, Drewes EJ and Engl B (2000) Physical and mechanical properties of iron-aluminium-(Mn, Si) lightweight steels, Revue de Metall, 97, 10:1245-1253.

[29] Raabe D (2003) Overview of basic types of hot rolling textures of steels, Steel Res Int 74:327-337.

[30] Suwas S, Toth LS, Fundenberger JJ, Grosdidier T and Skrotzki W (2005) Texture Evolution in FCC Metals during Equal Channel Angular Extrusion (ECAE) as a Function of Stacking Fault Energy, Sol State Phenom 105:345-350.

[31] Vercammen S, Blanpain B, Cooman BCD and Wollants P (2004) Cold rolling behaviour of an austenitic $\mathrm{Fe}-30 \mathrm{Mn}-3 \mathrm{Al}-3 \mathrm{Si}$ TWIP-steel: the importance of deformation twinning, Acta Mater 52(7):2005-2012. 
[32] Bracke L, Verbeken K, Kestens L and Penning J (2009) Microstructure and texture evolution during cold rolling and annealing of a high Mn TWIP steel, Acta Mater 57(5):1512-1524.

[33] Haase C, Chowdhury SG, Barrales-Mora LA, Molodov DA and Gottstein G (2013) On the Relation of Microstructure and Texture Evolution in an Austenitic Fe-28Mn-0.28C TWIP Steel During Cold Rolling, Metall and Mater Trans A 44(2):911-922.

[34] Hirsch J, Lucke K and Hatherly M (1988) Overview No. 76: Mechanism of deformation and development of rolling textures in polycrystalline f.c.c. Metals-III. The influence of slip inhomogeneities and twinning, Acta Metall 36:2905-2927.

[35] Saleh AA, Pereloma EV and Gazder AA (2011) Texture evolution of cold rolled and annealed Fe-24Mn-3Al-2Si-1Ni-0.06C TWIP steel, Mat Sci Eng A 528:4537-4549.

[36] Beyerlein IJ and Toth LS (2009) Texture evolution in equal-channel angular extrusion, Prog Mater Sci 54:427-510.

[37] Suwas S, Massion RA, Toth LS, Eberhardt A, Fundenburger JJ and Skrotzki W (2006) Evolution of crystallographic texture during equal channel angular extrusion of copper: The role of material variables, Metall. Mater Trans A 37:739-753.

[38] Higuera-Cobos OF, Berrios-Ortiz JA and Cabrera JM (2014) Texture and fatigue behavior of ultrafine grained copper produced by ECAP, Mater Sci Eng A 609:273-282.

[39] Skrotzky W, Scheerbaum N, Oertel CG, Arrufat-Massion R, Suwas S, Toth LS (2007) Microstructure and texture gradient in copper deformed by equal channel angular extrusion, Acta Mater, 55:2013-2024.

[40] Li S, Beyerlein IJ, Alexander DJ, Vogel SC (2005) Texture evolution during multipass equal channel angular extrusion of copper: neutron diffraction characterization and polycrystal modelling, Acta Mater, 53:2111-2121.

[41] Benito JA, Cobo R, Lei W, Calvo J and Cabrera JM (2016) Stress-strain 
response and microstructural evolution of a FeMnCAl TWIP steel during tension-compression tests, Mater Sci Eng A 655:310-320.

[42] Bouaziz O, Allain S and Scott C (2008) Effect of grain and twin boundaries on the hardening mechanisms of twinning-induced plasticity steels, Scripta Mater 58:484-487.

[43] Gil-Sevillano J (2009) An alternative model for the strain hardening of FCC alloys that twin, validated for twinning-induced plasticity steel, Scripta Mater 60:336-339.

[44] Barbier D, Gey N, Allain S, Bozzolo N and Humbert M (2009) Analysis of the tensile behavior of a TWIP steel based on the texture and microstructure evolutions, Mater Sci Eng A 500:196-206.

[45] Idrissi H, Renard K, Ryelandt L, Schryvers D and Jacques PJ (2010) On the mechanism of twin formation in Fe-Mn-C TWIP steels, Acta Mater $58: 2464-2476$

[46] Qu S, An XH, Yang HJ, Huang CX, Yang G, Zang QS, Wang ZG, Wu SD and Zhang ZF (2009) Microstructural evolution and mechanical properties of $\mathrm{Cu}-\mathrm{Al}$ alloys subjected to equal channel angular pressing, Acta Mater 57:1586-1601.

[47] Hughes DA, Lebensohn RA, Wenk HR and Kumar A (2000) Stacking fault energy and microstructure effects on torsion texture evolution, Proc of the royal soc A 1996;456:921-953.

[48] Jin JE and Lee YK (2009) Strain hardening behavior of a Fe-18Mn-0.6C-1.5Al TWIP steel, Mater Sci Eng A 527:157-161.

[49] Jin JE and Lee YK (2012) Effects of Al on microstructure and tensile properties of C-bearing high Mn TWIP steel, Acta Mater 60:1680-1688.

[50] Gutierrez-Urrutia I and Raabe D (2011) Dislocation and twin substructure evolution during strain hardening of an Fe-22 wt.\% Mn-0.6 wt.\% C TWIP steel observed by electron channeling contrast imaging, Acta Mater 59:6449-6462.

[51] Estrin Y, Vinogradov A (2013) Extreme grain refinement by severe plastic deformation: A wealth of challenging science, Acta Mater 61:782-817

[52] Barbier D, Favier V, Bolle B (2012) Modelling the deformation textures and 
microstructural evolutions of a Fe-Mn-C TWIP steel during tensile and shear testing, Mater Sci and Eng A 540:212-225.

[53] Chowdhury SG, Gubizca J, Mahato B, Chinh NQ, Hegedus Z, Langdon TG (2011) Texture evolution during room temperature ageing of silver processed by equal-channel angular pressing, Scripta Mater 64:1007-1010.

[54] Gazder AA, Torre FD, Gu CF, Davies CHJ, Pereloma EV (2006) Microstructure and texture evolution of BCC and FCC metals subjected to equal channel angular extrusion, Mater Sci and Eng 55:126-139.

[55] Skrotzki W, Scheerbaum N, Oertel CG, Brokmeier HG, Suwas S, Toth LS (2005) Texture gradient in ECAP silver measured by synchrotron radiation, Mater Sci Forum 495-497:821-826

[56] Suwas S, Toth LS, Fundenberger JJ, Eberhardt A, Skrotzki W (2003) Evolution of crystallographic texture during equal channel angular extrusion of silver, Scr Mater 49:1203-1206.

[57] Beyerlein IJ, Toth LS, Tomé CN, Suwas S (2007) Role of twinning on texture evolution of silver during equal channel angular extrusion, Phil Mag 87:885-906. 


\section{TABLES AND FIGURES}

Table 1

Chemical composition in \%mass and stacking fault energy of the TWIP steel of this study.

\begin{tabular}{|c|c|c|c|c|c|}
\hline $\mathrm{C}$ & $\mathrm{Mn}$ & $\mathrm{Si}$ & $\mathrm{Al}$ & $\mathrm{Fe}$ & SFE \\
\hline 0.5 & 20.1 & 1.23 & 1.72 & Bal. & $27.3 \mathrm{~mJ} / \mathrm{m}^{2}$ \\
\hline
\end{tabular}

Table 2

Mechanical properties (defined from the true stress - true strain curves) of the studied TWIP steel in different conditions

\begin{tabular}{|c|c|c|c|c|c|c|}
\hline $\begin{array}{c}\text { ECAP } \\
\text { schedules }\end{array}$ & $\begin{array}{c}\text { YS } \\
(\mathrm{MPa})\end{array}$ & $\begin{array}{c}\text { UTS } \\
(\mathrm{MPa})\end{array}$ & YR & $\begin{array}{c}\text { Elongation to } \\
\text { fracture }(\%)\end{array}$ & $\begin{array}{c}\text { Tensile } \\
\text { toughness } \\
\left(\mathrm{J} / \mathrm{m}^{3}\right) \times 10^{3}\end{array}$ & $\begin{array}{c}\text { Reduction of } \\
\text { area } \\
(\% \mathrm{RA})\end{array}$ \\
\hline $\begin{array}{c}\text { Initial } \\
\text { condition }\end{array}$ & 590 & 1370 & 0.43 & 40 & 489.3 & $64 \%$ \\
\hline 1 PASS & 1150 & 1400 & 0.82 & 19 & 256.5 & $36 \%$ \\
\hline 2 PASS & 1390 & 1520 & 0.91 & 14 & 224.4 & $28 \%$ \\
\hline 4 PASS & 1490 & 1600 & 0.93 & 7 & 97.5 & $19 \%$ \\
\hline
\end{tabular}

Table 3

Information of the microstructure of the ECAPed TWIP steel.

\begin{tabular}{|c|c|c|c|}
\hline \multirow{2}{*}{ ECAP PASS } & $\begin{array}{c}\text { Grain size of new formed } \\
\text { grains }(\mu \mathrm{m})\end{array}$ & \multicolumn{2}{|c|}{ Misorientation } \\
\cline { 2 - 4 } & 99.0 & 92.9 & LAGB $(\%)$ \\
\hline Initial condition & $4.1 \pm 2$ & 40.5 & 5.1 \\
\hline 1 pass & $1.2 \pm 0.6$ & 41 & 59.5 \\
\hline 2 passes & $0.4 \pm 0.2$ & 51.1 & 48.9 \\
\hline 4 passes & & & \\
\hline
\end{tabular}

Table 4

Dislocation density of TWIP steels of different passes

\begin{tabular}{|c|c|c|c|c|}
\hline Number of pass & 0 pass & 1 pass & 2 pass & 4 pass \\
\hline Dislocation density $\left(\mathrm{m}^{-2}\right)$ & $1.31 \times 10^{13}$ & $7.65 \times 10^{14}$ & $2.64 \times 10^{15}$ & $4.33 \times 10^{15}$ \\
\hline
\end{tabular}




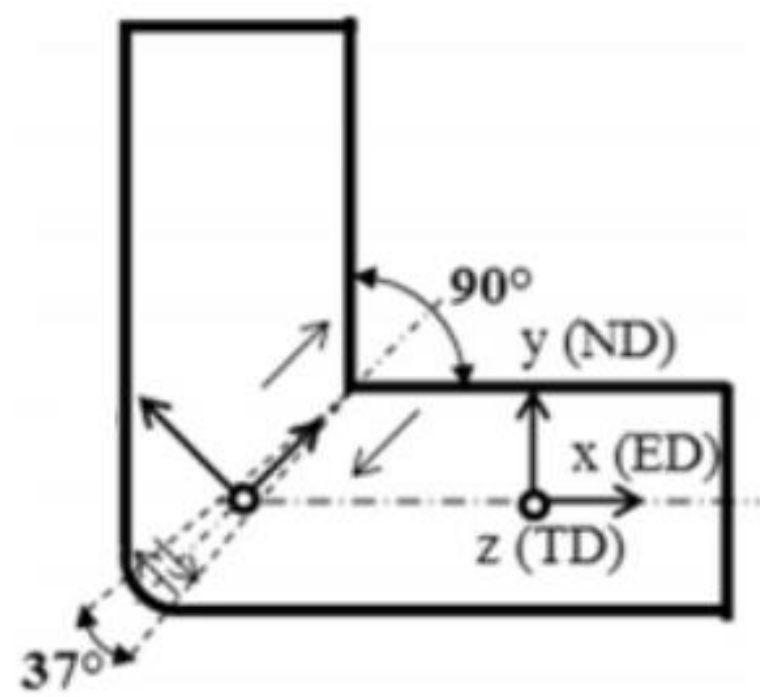

Fig. 1 ECAP die configuration and the corresponding coordinates system used in current research; ND (normal direction), ED (extrusion direction) and TD (transverse direction)

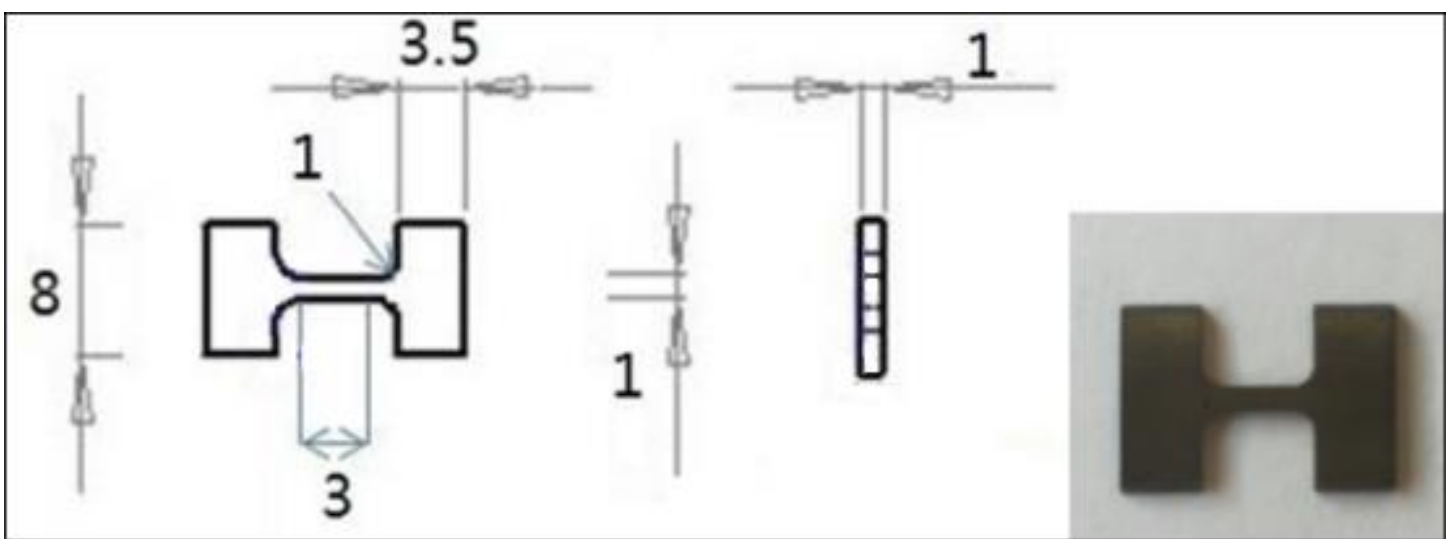

Fig. 2 Dimensions of micro-tensile samples (in $\mathrm{mm}$ ). 


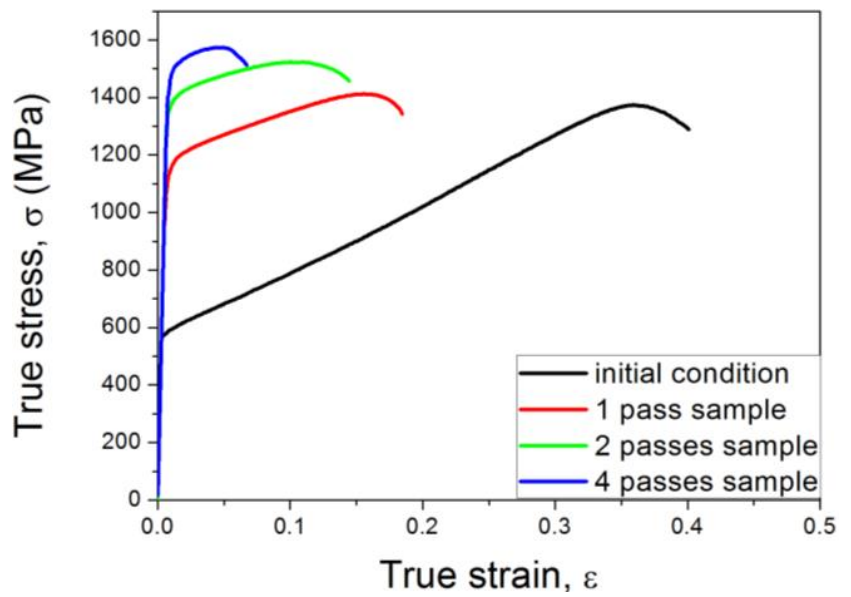

Fig. 3 True stress vs. True strain tensile curves for the samples before and after ECAP 

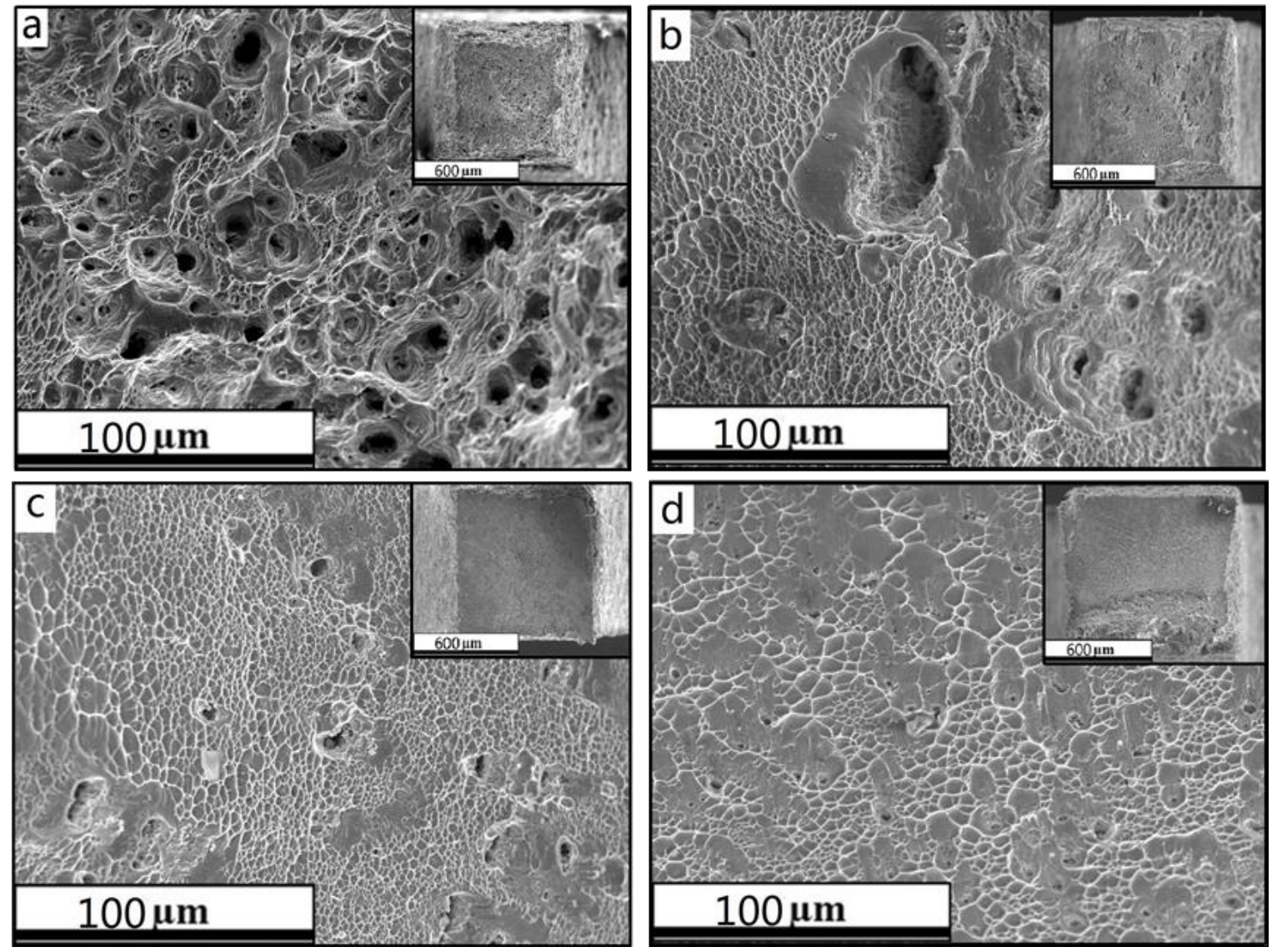

Fig. 4. Fracture surface of TWIP steel: (a) initial condition, (b) 1 pass, (c) 2 passes, and (d) 4 passes samples 


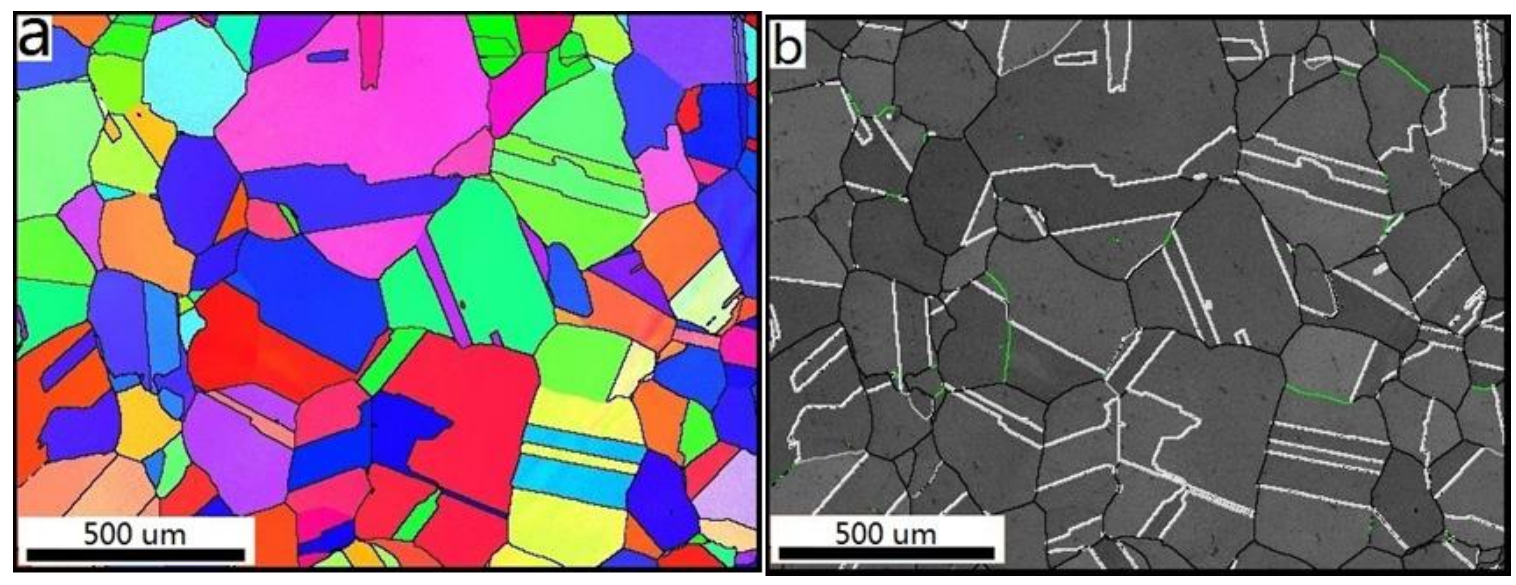

Fig. 5. EBSD grain map (a), and grain boundary map (b) of initial TWIP steel samples (grain boundary map: black line-high angle grain boundary, green line-low angle grain boundary, white line-twin boundary) 

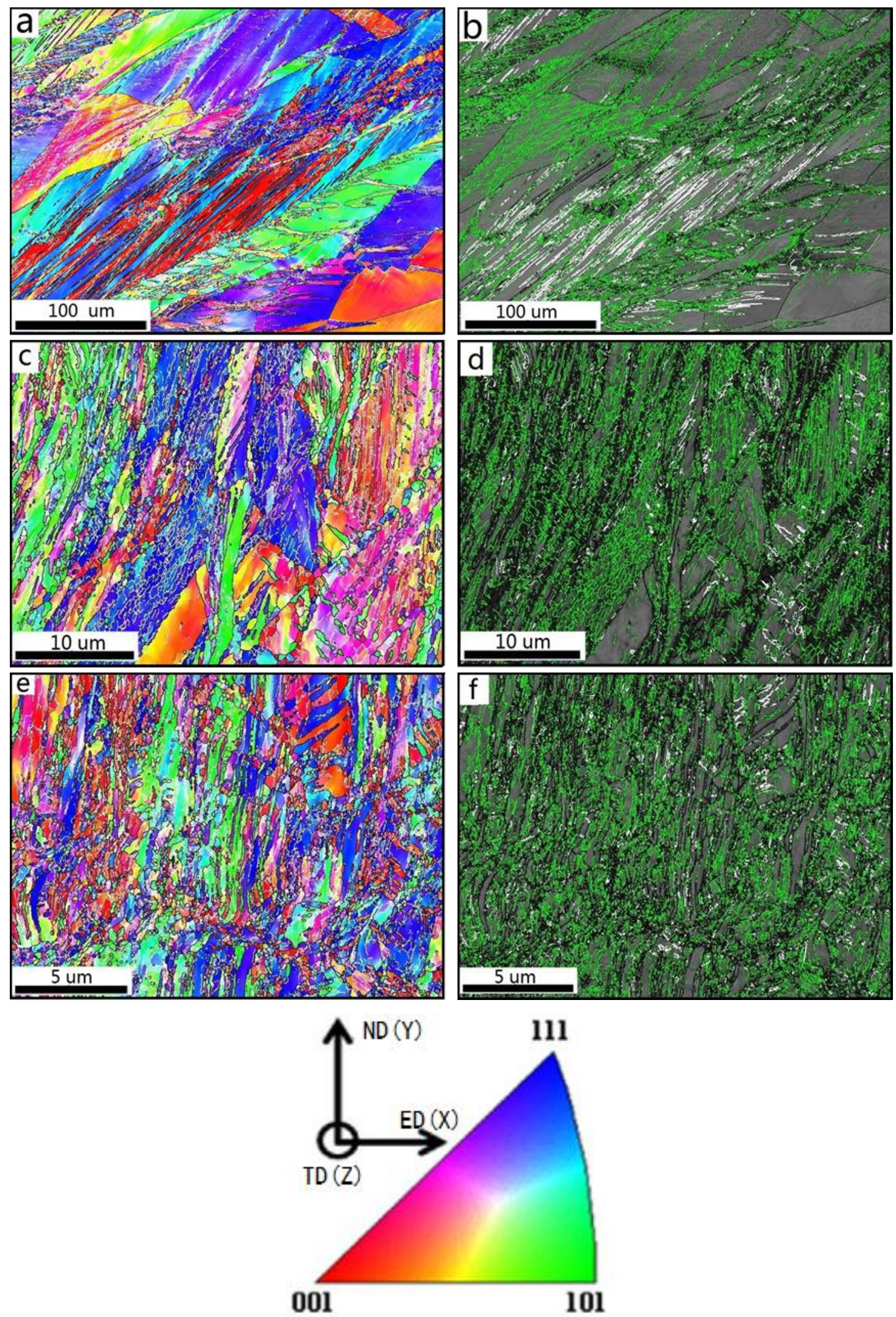

Fig. 6. EBSD grain map and grain boundary map of: 1 pass sample $(a, b), 2$ passes sample $(c, d)$ and 4 passes sample (e, f), (grain boundary map: black line-high angle grain boundary, green line-low angle grain boundary, white line-twin boundary) 

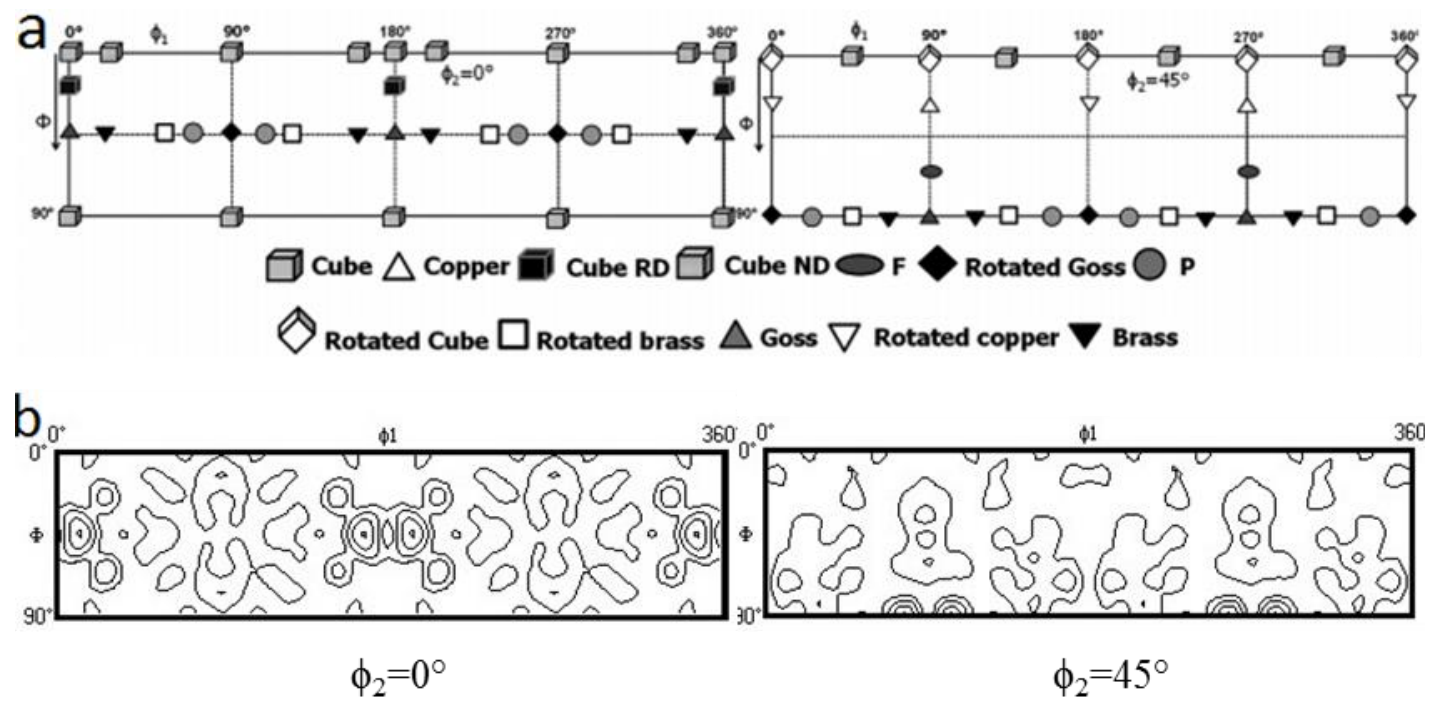

Contour isolevels: $1 / 3 / 7 / 10$

Fig. 7. ODF (a) ideal component [38] (b) initial conditions of investigated samples. 


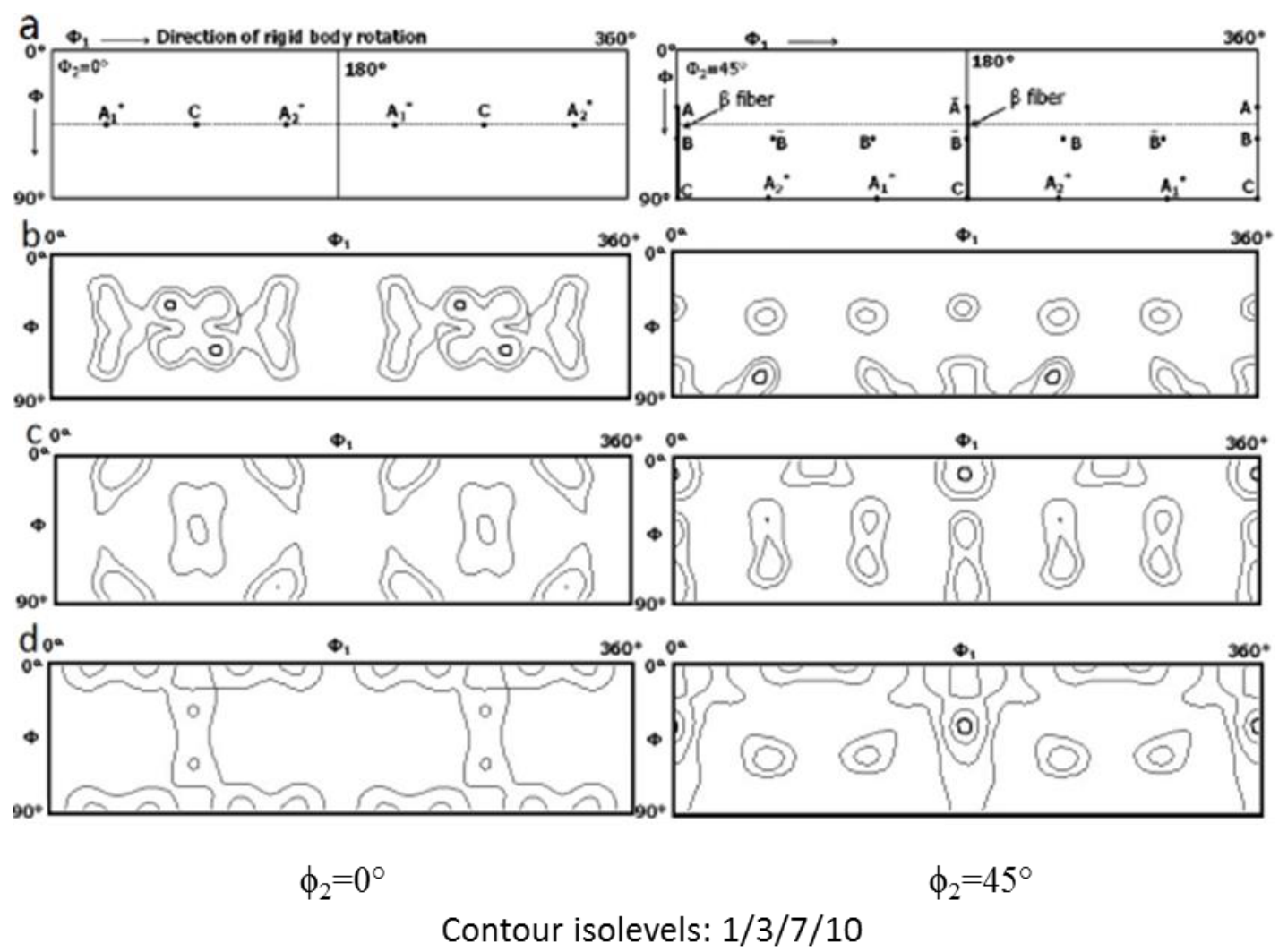

Fig. 8. (a): Ideal components in triclinic symmetry of FCC materials deformed by simple shear [36], (b)-(d):Texture components of investigated TWIP steels after (b) 1 ECAP pass , (c) 2 ECAP passes, and (d) 4 ECAP passes 


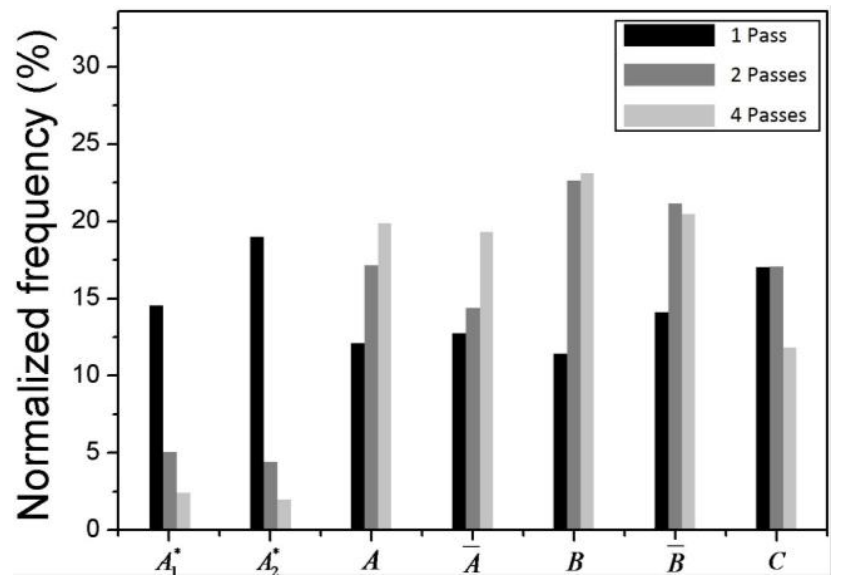

Fig. 9. Normalized frequency of main shear texture component for the investigated TWIP steel after ECAP process. (a) 1pass, (b) 2 passes and (c) 4 passes 


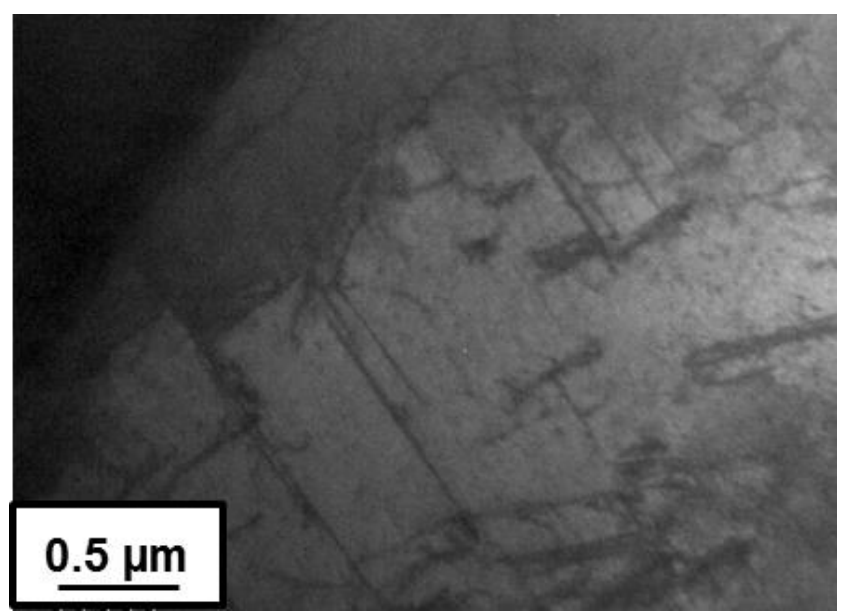

Fig. 10. TEM bright field images of initial condition TWIP steels

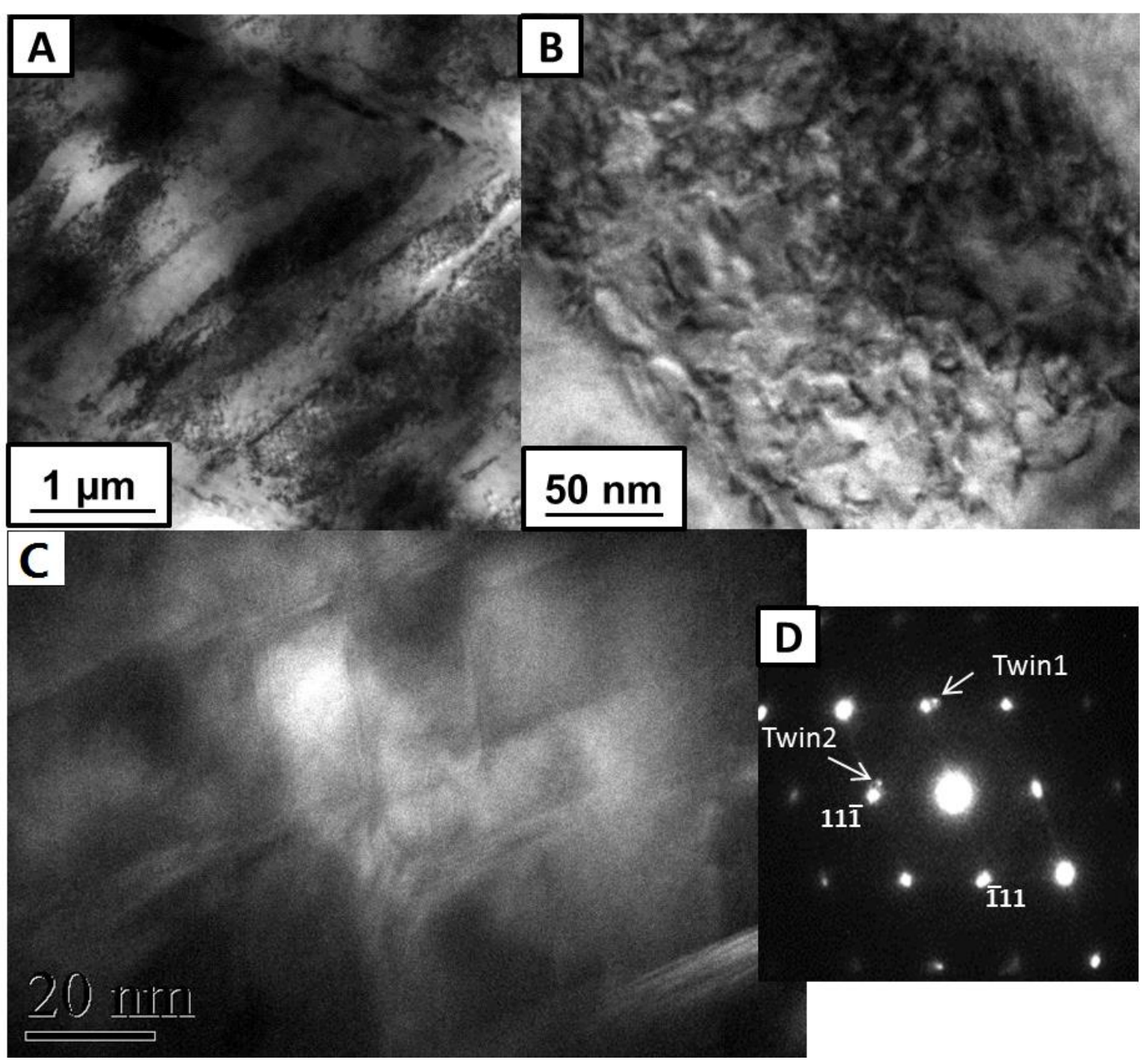

Fig. 11. TEM micrographs of one pass at $300^{\circ} \mathrm{C}$ : (a) general view of twins; (b) high density of dislocations inside a twin(c) Dark field image of an area with secondary twinning (d) SAED experimental pattern of (c) 


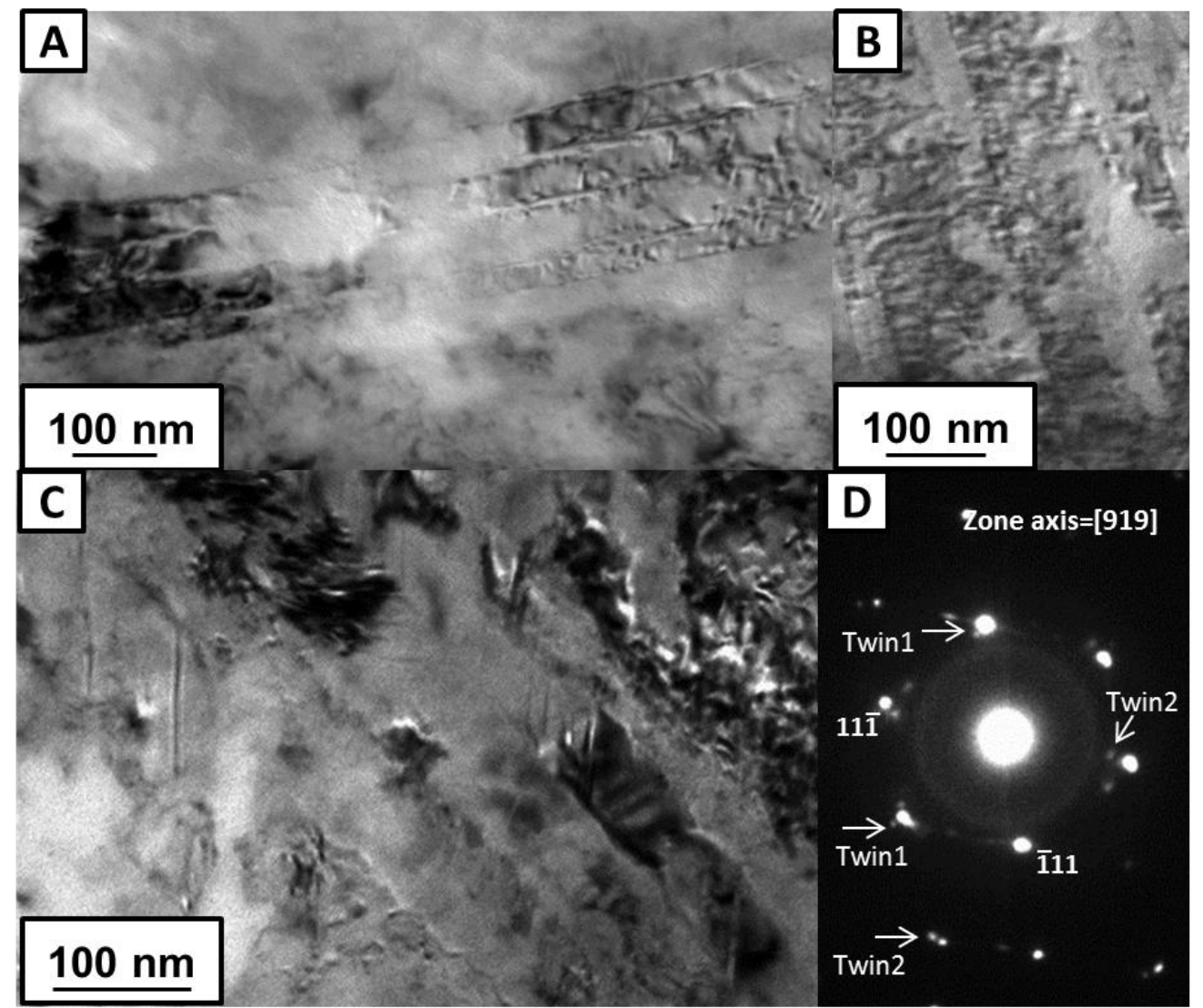

Fig. 12. TEM micrographs of two passes at $300^{\circ} \mathrm{C}$ : (a) general view of twins;

(b) high dislocation density inside twins; (c) secondary twinning inside primary twins; (d) SAED pattern of (c)

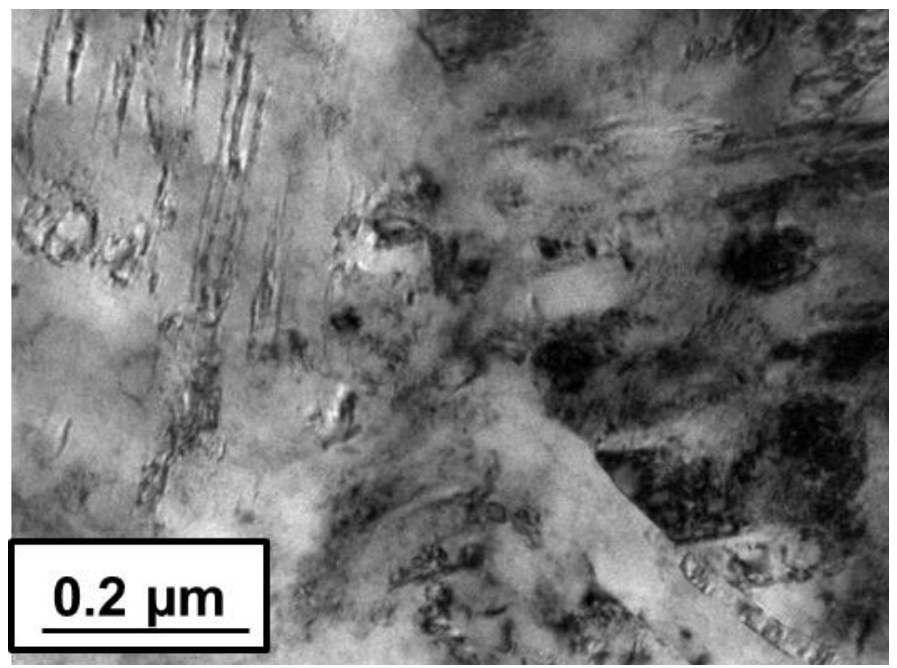

Fig. 13. TEM micrograph for four ECAP passes at $300^{\circ} \mathrm{C}$ 

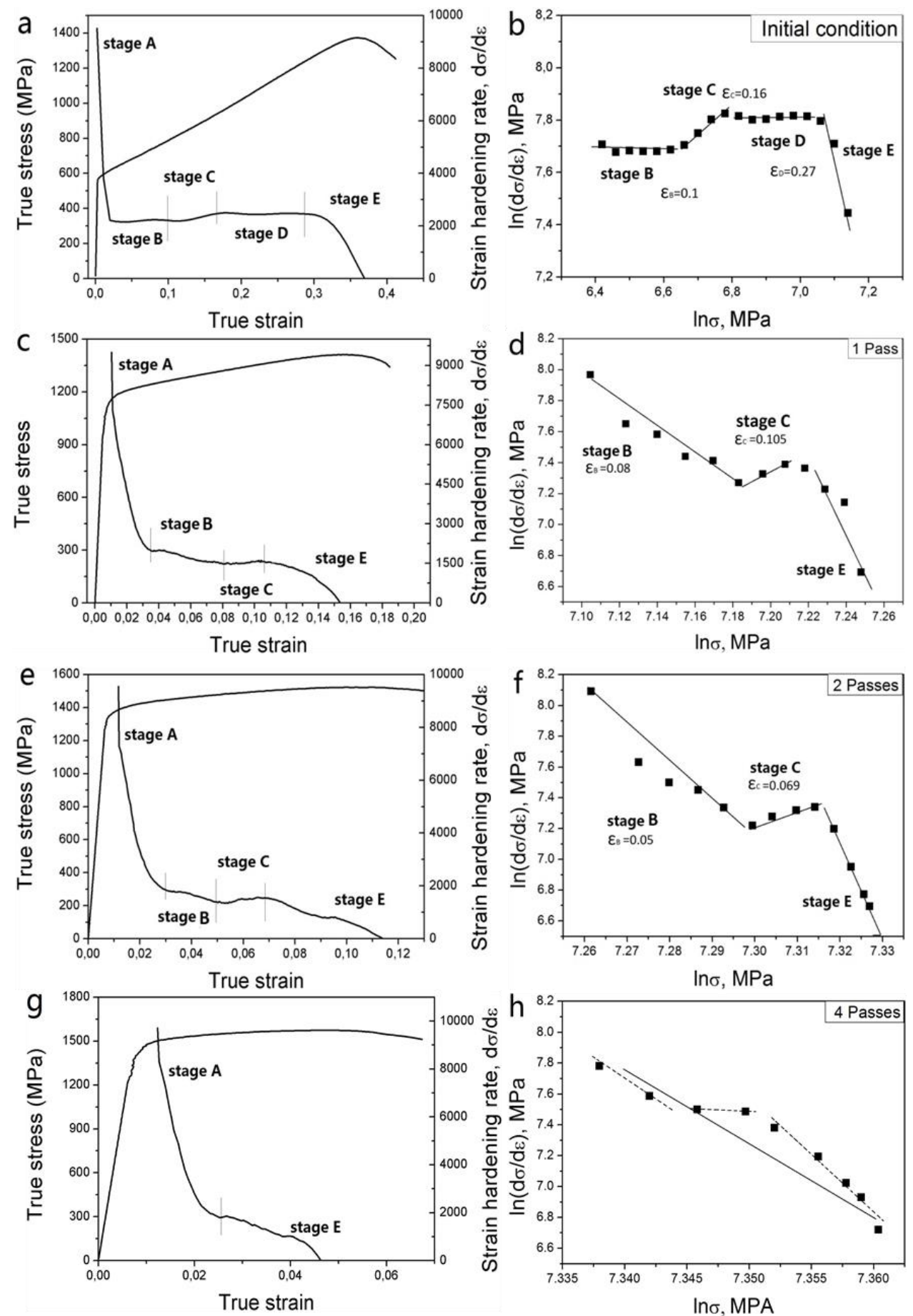

Fig. 14. True tensile stress $(\sigma)$-strain $(\varepsilon)$ curve, strain hardening rate $(\mathrm{d} \sigma / \mathrm{d} \varepsilon)$ and the plot of $\ln (\mathrm{d} \sigma / \mathrm{d} \varepsilon)$ vs. $\ln \sigma$ of the: (a) and (b) initial condition sample, (c) and (d) 1 pass sample, (e) and (f) 2 passes sample, (g) and (h) 4 passes sample. 